\title{
8 \\ Gender differences in costs and returns to higher education
}

\author{
Mathias Sinning
}

This chapter contributes to the work on gender equality in Australia's tax-transfer system from a higher education perspective. Investments in education are associated with costs and returns. The costs of higher education are closely linked to the Australian tax system through the Higher Education Contribution Scheme (HECS), which is administered by the Australian Taxation Office and involves student loan repayments based on taxable income. The returns to higher education-the earnings resulting from investing in education-are immediately relevant from a personal income tax perspective and affect the likelihood of receiving transfer payments. Consequently, gender differences in costs and returns to higher education have important implications for the design of the tax-transfer system.

There are many reasons why people choose to pursue higher education in Australia. Some people want extra qualifications to help them advance in a specific career path. For many others-especially younger cohortshigher education is very attractive because they are not ready to enter the 'real' world of full-time work. A decision to undertake further studies involves opportunity costs and trade-offs: we spend years at an education institution to get the desired qualification(s); we could have started to work and be earning money if we were not studying; we have to pay for those textbooks when we are studying. The list of costs associated 
with undertaking further education goes on, but these investments are expected to reap returns in the future. According to the Organisation for Economic Co-operation and Development (OECD) (2015), on average having a tertiary education qualification translates into 34 per cent higher relative earnings of 24-64-year-olds in Australia. People with higher levels of education are also more likely to be employed, remain employed and have more opportunities to advance in their career.

Knowledge about the private returns to education is not just relevant for the decision of individuals to invest in higher education but may also have important implications for the design of education policies. Studies that estimate the private returns to education in Australia focus exclusively on analysing a 'snapshot' of the population at one point in time: that is, they either use cross-sectional data (see, for example, Daly et al. 2010; Norton 2012) or employ longitudinal data to perform a cross-sectional analysis (e.g. Leigh and Ryan 2008; Marks 2008).

Unfortunately, cross-sectional models ignore the relevance of age and time effects. In particular, age-earnings profiles obtained from cross-sectional data implicitly assume that, for example, the earnings of a 35-year-old person in 20 years will be the same as those of a (comparable) 55-year-old person today. It appears likely that this assumption is unrealistic because people who were observed at one point in time do not retain their position in the earnings distribution for the rest of their working lives. Individual earnings may change considerably over time for various reasons. Empirical studies suggest that observed characteristics (such as education and labour market experience) explain a relatively small proportion of earnings variability (Higgins and Sinning 2013). Unobserved differences can result from temporary variation (due to illness, higher duties, bonuses, overtime, etc.) or permanent variation (such as ability, talent or motivation).

Against this background, this chapter generates new estimates of the private returns to higher education for women and men in Australia, using longitudinal data from the Household, Income and Labour Dynamics in Australia (HILDA) Survey, which follows a representative sample of the Australian population over the period 2001-14. The data allow us to compare the estimates obtained from a cross-sectional model to those of a longitudinal model that considers both age and time effects. The use of HILDA data limits our analysis to relatively small samples, and, in contrast to (cross-sectional) Census data, HILDA does not permit a disaggregated estimation of private returns to education by sub-group 
(such as field of study). However, the focus on HILDA data allows us to understand the relevance of longitudinal aspects when estimating private returns to education. Our analysis focuses on the calculation of average returns to education and therefore does not require a consideration of temporary and permanent variation in earnings. This is because dynamic panel data models typically assume that the model error terms are normally distributed with mean zero.

The chapter focuses on private returns - the private benefits from higher education. Specifically, we compare earnings of individuals with higher education and those with education at Year 12 and below to calculate the present value of lifetime earnings resulting from higher education. A complete analysis of the value of higher education would involve a comparison of the benefits to the costs associated with higher education. Although such a cost-benefit analysis is beyond the scope of this paper, we are able to study the implications of gender differences in earnings over the life course for the financial capacity of male and female university graduates to repay income contingent student loans. Guyonne Kalb, in Chapter 5, also takes a life course approach, looking at the effect of taxes and expenditure on labour supply. The Australian HECS, which was introduced in 1989 to finance tuition fees of Australian university students, constitutes an excellent example that allows us to illustrate the link between gender differences in earnings and gender differences in student loan repayments. Our discussion of student loan repayments relies on findings of Higgins and Sinning (2013) who pay particular attention to the importance of dynamic earnings modelling for the design of income-contingent student loans.

Our analysis of private returns to education reveals that lifetime earnings of men with a postgraduate degree (Master's or Doctorate) are about 83 per cent higher than those of men with Year 12 and below. Women with a postgraduate degree earn about 50 per cent more over their lifetime than women with Year 12 and below. Our findings also reveal that lifetime earnings of women with a Bachelor or Honours degree are about as high as those of women with a postgraduate degree. We further observe that women have no benefits from investing in vocational training. Gender differences in earnings have considerable implications for the repayment of income-contingent student loans. The average outstanding debt of male university graduates converges to zero over a 30 -year period, whereas the 
average outstanding debt of female university graduates remains positive, indicating that many female university graduates in Australia do not have the financial capacity to repay their student loans in full.

The following section provides an overview of the literature on the estimation of private returns to education. The third section describes the data and provides some descriptive statistics. Our empirical strategy is explained in the fourth section. The main results are discussed in the fifth section. The sixth section illustrates the implications of gender differences in earnings for the repayment of income-contingent student loans. The seventh section provides a short discussion of the results. The final section concludes.

\section{The literature on returns to education}

The economic literature on the estimation of the returns to education is motivated by the human capital framework (Becker 1964), which considers education an investment in human capital. Extensive literature across many countries and time periods has shown that highly educated people generally earn more than less educated people (see Ashenfelter et al. (1999) and Psacharopoulos and Patrinos (2004) for surveys of the literature).

Most empirical studies use the human capital earnings function derived by Mincer (1974) to estimate the returns to education. The human capital earnings function relates the (logarithm of) earnings to the number of years of education and labour market experience. Education was typically measured in years, but many studies have adopted alternative model specifications that take into account that education is better represented by certain degrees rather than the number of years of education (see, for example, Jaeger and Page 1996).

The model includes labour market experience to isolate effects of on-thejob training on earnings from the effect of education on earnings. The original human capital earnings function includes a quadratic function of labour market experience to take into account that earnings typically increase at a declining rate and that increasing labour market experience may even reduce earnings at the end of the working life. It is unclear whether older workers suffer from declining productivity towards the end of their working life or whether the decline in earnings simply reflects 
different work-leisure preferences and, therefore, reduced hours of work (but at the same level of productivity). Our analysis focuses on the study of hourly wages to address this issue and to facilitate comparisons between male and female workers. Sections 3 and 4 provide a detailed discussion of earnings measures.

A large strand of the empirical literature on the returns to education has focused on a problem that is caused by unobservable variables that are correlated with education, such as individual ability or talent. The omission of these variables may lead to a bias in the estimated returns to education, and numerous studies have employed empirical strategies that allow them to identify the causal effect of education on earnings. These studies have typically employed instrumental variables strategies (Angrist and Krueger 1991; Card 1999) or made use of twin studies (Ashenfelter and Krueger 1994) to identify the causal effect of education on earnings. On balance, these studies show that the bias caused by unobservable variables is relatively small.

It is important to note that the human capital earnings function ignores the (monetary or non-monetary) costs of education. Monetary costs do not only include direct costs such as fees, books and equipment but also opportunity costs resulting from foregone earnings as a result of spending time in education. Heckman et al. (2005) conclude that non-monetary (psychic) costs of education are substantial, which may explain why many people do not invest in higher education, even if the returns to education are high.

An alternative approach to make inferences about the private returns to education is to calculate the net present value of an investment in education (Becker 1964; Schultz 1961). The net present value is the difference between the discounted present value of lifetime earnings and the discounted present value of the costs of investing in education. The calculation depends on a discount rate, which takes into account that the value of present earnings is higher than the value of future earnings.

The calculation of the net present value of an investment in education is typically based on the comparison of earnings of workers with Year 12 and below and workers who receive tertiary education and face direct costs. Opportunity costs can be obtained by assuming that if individuals with tertiary education had not made the investment, their earnings would be 
the same as those of individuals with Year 12 and below. The approach requires the collection of data on the direct costs of education and typically ignores potential biases resulting from unobserved factors.

Numerous studies have estimated the private returns to education in Australia and shown that an investment in higher education is highly profitable (see Daly et al. 2010). Leigh and Ryan (2008) employ a human capital earnings function to estimate the returns to education and compared different empirical strategies (instrumental variables and twin studies) to address potential biases caused by unobserved ability. They conclude that the rate of return to an additional year of education, corrected for ability bias, is around 10 per cent. Daly and Lewis (2010) study the net present value of investing in education and find that this approach produces higher returns to education than the preferred estimate reported by Leigh and Ryan (2008). Wei (2010) compares the returns to education obtained from a human capital earnings function to those of the net present value calculation and finds that the results obtained from the latter approach are higher.

Norton (2012) uses data from the 2006 Census and finds that at the median, lifetime earnings of men with a Bachelor degree are 65 per cent higher than those of men with Year 12 and below. The difference for women at the median is close to 80 per cent. Norton (2012) also studies the range of graduate earnings and concludes that the majority of graduates benefit from university education within each discipline with the exception of men studying performing arts.

The economic literature in Australia focuses exclusively on the crosssectional analysis of private returns to education and ignores dynamic aspects of lifetime earnings. Unfortunately, age-earnings profiles based on cross-sectional models assume that, for example, the earnings of an average 35-year-old university graduate in 20 years will be as high as today's earnings of an average 55-year-old university graduate. This assumption may have severe consequences for the estimation of private returns to education.

Our analysis contributes to the empirical literature on the private returns to education in two important ways. First, we use hourly wages as an outcome measure to estimate private returns to education because they facilitate comparisons between men and women who exhibit very different levels of labour supply. Instead of using annual earnings 
(measured in dollars) to calculate lifetime earnings, we use annual averages of hourly wages to study wage differentials (measured in per cent) between different levels of education. The present value of these differentials may be used to calculate private returns to education (measured in per cent). Second, we use longitudinal data to consider both age and time effects (and the interaction between age and time) to predict future wages.

\section{Data and descriptive statistics}

\section{Data}

Our empirical analysis uses data from the HILDA panel for the period 2001-14. The first wave of the longitudinal survey consisted of 7,682 households and 19,194 individuals. The survey follows these households over time and all adult members of each household are interviewed annually. In 2011, a top-up sample was added to the survey to address sample attrition. The top-up sample will not be considered in our analysis to avoid potential inconsistencies resulting from the consideration of additional households.

The HILDA panel contains information about a range of topics, including individual earnings, educational attainment and labour market experience. In our cross-sectional analysis, we will compare three earnings measures, which produce slightly different results: hourly wages, weekly earnings and annual earnings. Our longitudinal analysis focuses on hourly wages, which facilitate comparisons between men and women who exhibit very different levels of labour supply.

To obtain representative results for Australia, we do not impose many restrictions on our analysis sample. Our analysis is based on an unbalanced panel: we include individuals who enter a survey household during the survey period. We restrict our analysis sample to 25-64-year-old persons who are either full- or part-time employed and who report positive annual earnings. We do not consider the top 0.1 per cent of the hourly wage and annual earnings distribution and we drop individuals who report (positive or negative) business income to avoid potential biases caused by outliers that are not necessarily representative. 
Our analysis is performed separately for men and women because it appears likely that they will have different returns to education. After dropping individuals who do not report their education and labour market experience, our analysis sample includes 68,720 person-year observations (34,656 men and 34,064 women) over the period 2001-14. We employ person weights provided by HILDA throughout the entire analysis to obtain representative results.

\section{Descriptive statistics}

This section provides a description of the most important variables that we use to perform the empirical analysis. Table 8.1 includes average levels of education by gender in 2014 . We observe that about 7.2 per cent of the male workers and 10.3 per cent of female workers in Australia have a postgraduate degree (Master's or Doctorate).

Female workers are also more likely to have a Bachelor or Honours degree or an Advanced Diploma/Diploma than male workers. The share of female workers with a Bachelor or Honours degree is 23.9 per cent, and the corresponding share of male workers is 19.0 per cent. Advanced Diploma/Diploma holders make up 13.3 per cent of female workers and 12.2 per cent of male workers.

In contrast, men are considerably more likely to have a Certificate I-IV then women. The share of male Certificate I-IV holders is 33.1 per cent, compared to 21.2 per cent of female Certificate I-IV holders. The fractions of male and female workers with Year 12 and below are 28.5 per cent and 31.4 per cent, respectively.

Table 8.1: Education by gender, 2014

\begin{tabular}{|l|c|c|}
\hline \multirow{2}{*}{ Postgraduate Degree (Masters or Doctorate) } & Men & Women \\
\cline { 2 - 3 } & 0.072 & 0.103 \\
\hline \multirow{2}{*}{ Bachelor or Honours } & $(0.259)$ & $(0.303)$ \\
\cline { 2 - 3 } & 0.190 & 0.239 \\
\hline \multirow{2}{*}{ Advanced Diploma or Diploma } & $(0.392)$ & $(0.426)$ \\
\hline Certificate I-IV & 0.122 & 0.133 \\
\cline { 2 - 3 } & $(0.327)$ & $(0.339)$ \\
\cline { 2 - 3 } & 0.331 & 0.212 \\
\hline
\end{tabular}




\begin{tabular}{|l|c|c|}
\hline \multirow{2}{*}{ Without non-school qualification } & Men & Women \\
\hline \multirow{2}{*}{ Education in years } & 0.285 & 0.314 \\
\cline { 2 - 3 } & $(0.452)$ & $(0.464)$ \\
\hline Observations & 12.6 & 12.8 \\
\cline { 2 - 3 } & $(1.8)$ & $(2.0)$ \\
\hline
\end{tabular}

Weighted numbers based on weights provided by HILDA. Standard deviations are reported in parentheses.

Source: Author's own calculations based on HILDA data.

When comparing the average total number of years of education of male and female workers, gender differences in educational attainment appear rather small. On average, male workers have 12.6 years of education, whereas the average number of years of education of female workers is 12.8 years. These numbers suggest that we cannot simply assume that educational attainment is sufficiently described by the number of years of education. For that reason, we will take into account different levels of education in our empirical analysis.

We may also study the association between educational attainment and earnings of male and female workers. In this section, we compare three types of earnings measures: hourly wages, weekly earnings and annual earnings. Figure 8.1 presents average hourly wages by gender and education in 2012. We find that the average hourly wage of men with a postgraduate degree is about $\$ 46$. The average hourly wage of women with a postgraduate degree is only $\$ 39$.

Figure 8.1 also reveals that workers with higher levels of education generally earn more than less educated workers. Male workers with a Bachelor or Honours degree earn about $\$ 44$ per hour, those with an Advanced Diploma/Diploma earn about $\$ 37$, while average hourly wages of Certificate I-IV holders are about \$36, and male workers with Year 12 and below earn about $\$ 30$ per hour.

A slightly different picture emerges when we look at the sample of female workers. Female workers with a Bachelor or Honours degree earn about $\$ 39$ per hour, Advanced Diploma/Diploma holders earn about \$29, and Certificate I-IV holders earn on average about $\$ 25$, followed by female workers with Year 12 and below who earn about \$27. 


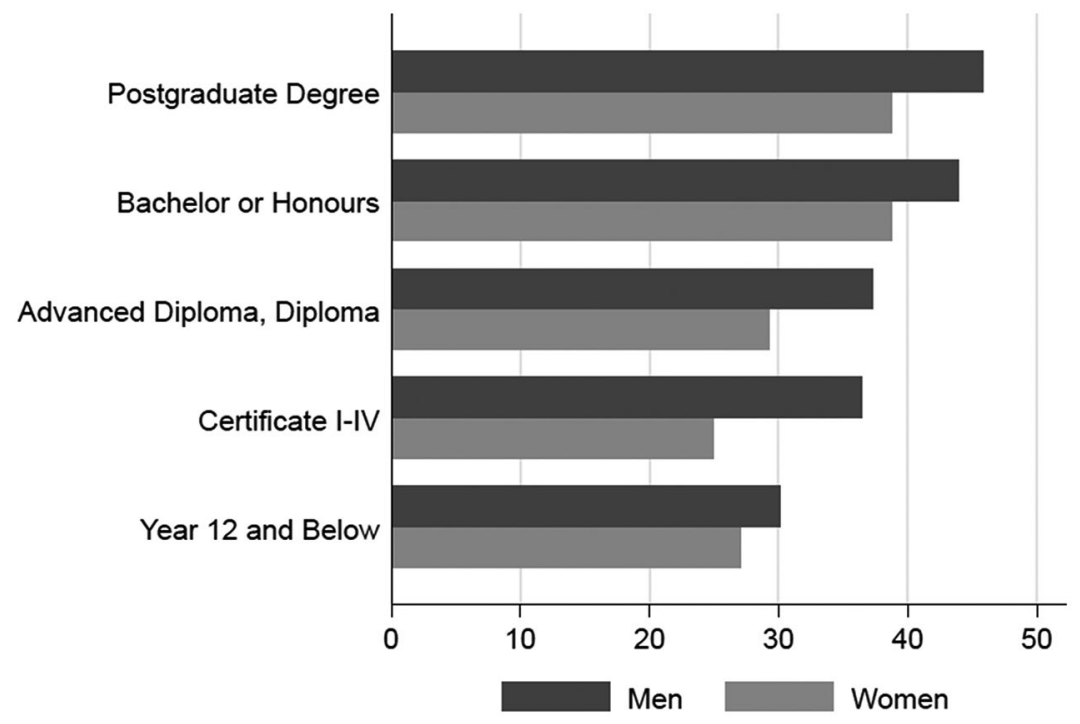

Figure 8.1: Hourly wages by gender and education, 2014

Weighted numbers based on weights provided by HILDA.

Source: Author's own calculations based on HILDA data.

The gender differences in average hourly wages presented in Figure 8.1 appear to be relatively small (only a few dollars), but they are in fact quite substantial. In particular, the earnings differentials between male and female workers become more obvious when we take into account that women are considerably less likely to be in full-time employment than men. For that reason, we also consider differences in weekly and annual earnings. Figure 8.2 presents average weekly earnings by gender and education in 2014 .

We observe a considerable gender earnings gap along the entire educational distribution. Specifically, we find that men with a postgraduate degree earn on average about $\$ 2,037$ per week, and that weekly earnings of women are only about $\$ 1,316$.

The earnings gap between male and female workers with Bachelor or Honours degree is slightly smaller (men with a Bachelor or Honours degree earn about $\$ 1,867$ and women earn about $\$ 1,289$ per week) and we observe large gaps between male and female workers with Advanced Diploma/Diploma ( $\$ 1,591$ vs $\$ 1,021$ per week) and Certificate I-IV ( $\$ 1,526$ vs $\$ 793$ per week). The earnings gap between male and female 
workers with Year 12 and below is smaller in absolute terms (men earn about $\$ 1,255$ and women earn about $\$ 830$ per week) but still substantial in relative terms (women earn about 40 per cent less than men).

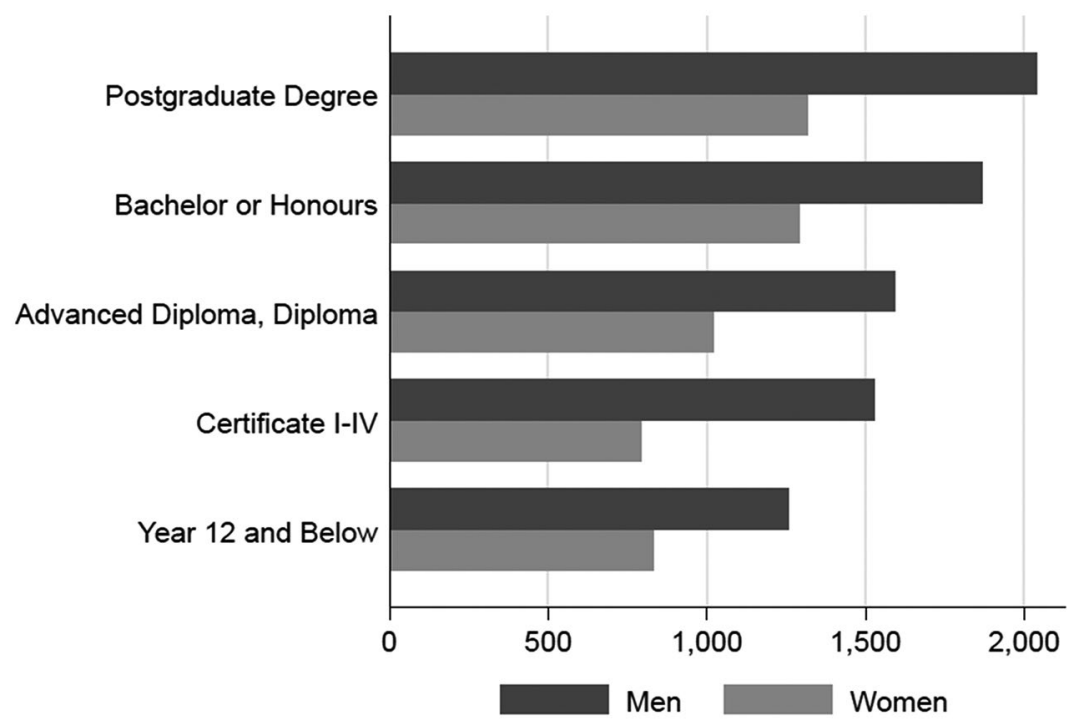

Figure 8.2: Weekly earnings by gender and education, 2014

Weighted numbers based on weights provided by HILDA.

Source: Author's own calculations based on HILDA data.

Figure 8.3 reveals how these differences translate into annual earnings differences. We find that average male workers with a postgraduate degree earn $\$ 107,908$ in 2014 . Average earnings of female workers with the same degree are $\$ 70,370$, largely because female workers are more likely to be part-time employed.

Average annual earnings of male workers seem to increase by about $\$ 10,000-\$ 15,000$ for each level of education considered in our analysis: average male workers with Year 12 and below earn about $\$ 65,402$, those with a Certificate I-IV earn about $\$ 77,662$, average earnings of Advanced Diploma/Diploma holders are about $\$ 84,446$, and male workers with a Bachelor or Honours degree earn on average about $\$ 99,455$. 


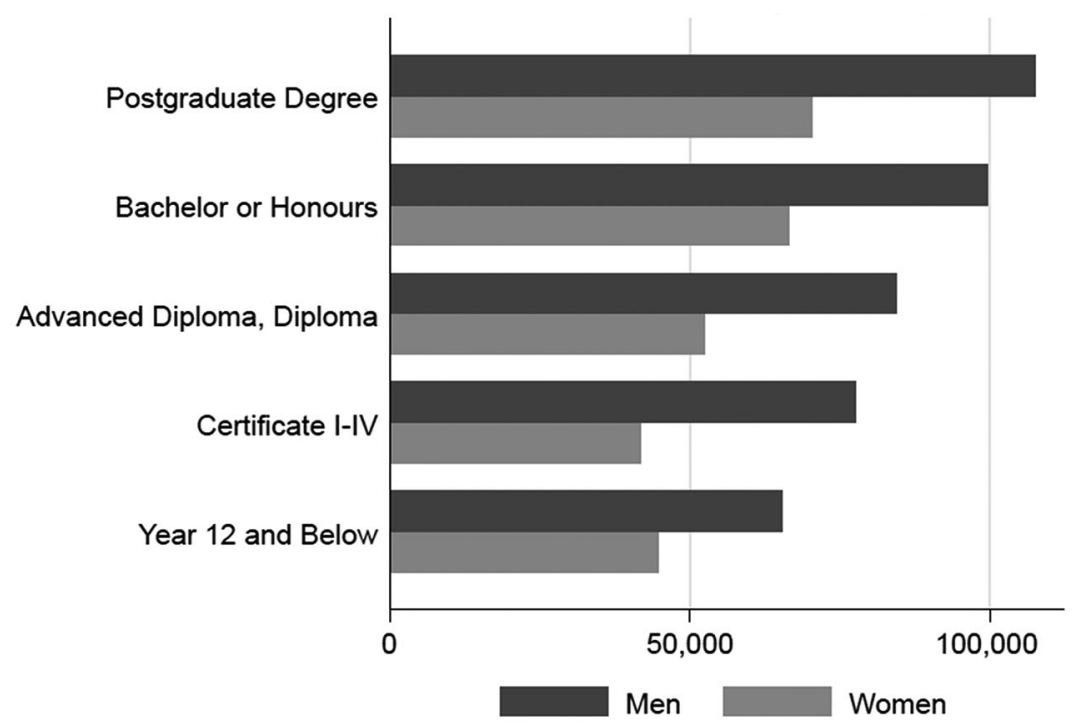

Figure 8.3: Annual earnings by gender and education, 2014

Weighted numbers based on weights provided by HILDA.

Source: Author's own calculations based on HILDA data.

In contrast, we do not find a linear increase in average annual earnings of female workers across the educational distribution. Female workers with Year 12 and below earn on average $\$ 44,760$ per year, slightly more than average female workers with a Certificate I-IV, who earn about $\$ 41,799$. Average annual earnings of female workers with Advanced Diplomal Diploma are $\$ 52,406$, while workers with a Bachelor or Honours degree earn about $\$ 66,547$.

Taken together, the results presented in Figures 8.1-8.3 highlight considerable earnings differentials both between male and female workers and across the educational distribution of male and female workers. Average annual earnings of women are strongly affected by labour supply. Although highly educated women earn higher hourly wages than less educated women, they do not necessarily have higher annual earnings because less educated women may work relatively long hours. In our empirical analysis, we will focus on hourly wages to take into account that labour supply patterns differ considerably between men and women. 


\section{Methodology}

\section{Cross-sectional analysis}

The starting point of our empirical analysis is the conventional human capital earnings function (Mincer 1974), which relates individual earnings to education and labour market experience. The approach has served as the 'workhorse' of numerous cross-sectional studies over the last four decades. We use a linear regression model to estimate the rate of return to education. The human capital earnings function can be written as:

Equation 8.1

$\log \left(y_{i}\right)=\beta_{0}+\beta_{1} \operatorname{educ}_{i}+\beta_{2} \exp _{i}+\beta_{3} \exp _{i}^{2}+X_{i} \beta_{4}+u_{i}$,

where $y_{i}$ is one of the earnings measures (hourly wages, weekly earnings, annual earnings) used in our analysis, which refers to $i$ th individual in a sample consisting of $N$ observations $(i=1, \ldots, N)$. educ denotes the number of years of education of individual $i, \exp _{i}$ is the number of years of labour market experience, and $X_{i}$ is a set of additional control variables. We use a pooled sample over the time period 2001-14 in our analysis to estimate Equation 8.1 and therefore $X_{i}$ includes indicator variables for each year, which capture year-specific effects, such as inflation. We adjust the standard errors of the model to take into account that we observe the same individuals repeatedly in our pooled sample. $u_{i}$ is the model error term and $\beta_{0}, \beta_{1}, \ldots, \beta_{4}$ are the model parameters that have to be estimated. We are particularly interested in the parameter $\beta_{4}$, which measures the average effect of an additional year of education on earnings, given that all other factors remain unchanged. Our estimates of the human capital earnings function are presented in Tables 8.2 and 8.3.

We also estimate a modified version of the human capital earnings function, which takes into account that the returns to education are different across the educational distribution. Our model can be written as:

Equation 8.2

$$
\begin{aligned}
\log \left(y_{i}\right) & =\gamma_{0}+\gamma_{1} \text { postgrad }_{i}+\gamma_{2} \text { bachelor }_{i}+\gamma_{3} \text { diploma }_{i} \\
& +\gamma_{4} \text { certificate }_{i}+\gamma_{5} \exp _{i}+\gamma_{6} \exp _{i}^{2}+X_{i} \gamma_{7}+v_{i},
\end{aligned}
$$


where postgrad $_{i}$ is an indicator variable that takes on the value one if individual $i$ has a postgraduate degree and is equal to zero otherwise. bachelor $_{i}$ is an indicator variable for individuals with a Bachelor or Honours degree, diploma $a_{i}$ indicates an Advanced Diploma/Diploma, and certificate $_{i}$ indicates a Certificate I-IV. $v_{i}$ is the model error term and $\gamma_{0}$, $\gamma_{1}, \ldots, \gamma_{7}$ are the model parameters. The estimated parameters of the indicator variables may be interpreted relative to the omitted reference category, which consists of individuals with Year 12 and below.

The two linear regression models described above do not take into account that unobserved characteristics (such as ability) may be correlated with educational attainment, which could bias our returns to education estimates. We ignore the potential bias caused by unobserved characteristics because the empirical literature on the returns to education shows that the bias is relatively small (see Leigh and Ryan 2008) and because our analysis focuses on understanding the difference between cross-sectional and longitudinal earnings models. It appears unlikely that the bias caused by unobserved characteristics is very different between these models.

\section{Life-cycle analysis}

We compare the results obtained from the cross-sectional models described above to those of a life-cycle model that considers age and time effects (and the interaction between age and time). The estimates obtained from the life-cycle model allow us to predict future wages of male and female workers by level of education.

We consider actual wages observed in 2001 as a starting point to predict wages over the time period 2002-40. Our wage regression includes age indicators, a time trend and interactions between age and time. The estimated parameters allow us to predict age-wage profiles over a 40-year time period. These profiles may be used to calculate the present value, $P V$, of wage differentials (measured in per cent) between workers with comparable levels of labour supply but different levels of education. The present value of the expected returns can be written as:

Equation 8.3

$$
P V=\frac{B_{1}}{1+r}+\frac{B_{2}}{(1+r)^{2}}+\frac{B_{3}}{(1+r)^{3}}+\cdots+\frac{B_{T}}{(1+r)^{T}},
$$


where $B_{t}, t=1, \ldots, T$ is the benefit in period $t$ and $T$ is the total number of years. $r$ denotes the interest rate.

The following section presents the results of the cross-sectional and the longitudinal analysis described above.

\section{Results}

\section{Cross-sectional analysis}

The estimates of the human capital earnings function for the sample of male workers are presented in Table 8.2. The estimates are based on the linear regression of a pooled sample covering the time period 2001-14. The coefficient measuring the relationship between the number of years of education and hourly wages indicates that an increase in education by one year (given all other factors remain the same) led to an average increase in hourly wages by 8.6 per cent. We also observe a rate of return to education of 9 per cent when we use weekly earnings as a dependent variable in our model. Average annual earnings increase by 10.3 per cent if education increases by one year (and all other factors remain the same).

The coefficients on the number of years of labour market experience and labour market experience squared show that the increase in earnings resulting from an increase in labour market experience is significant, but that earnings increase with labour market experience at a declining rate. The constant term is relevant for the construction of the regression model but its interpretation is not very useful because it captures average earnings of individuals without education and labour market experience.

The ordinary least squares (OLS) estimates presented in Table 8.2 are comparable to other cross-sectional studies that present estimates of the human capital earnings function for other countries and/or time periods. 
Table 8.2: Returns to education of male workers: OLS estimates, 2001-14

\begin{tabular}{|l|c|c|c|}
\hline & Hourly wages & $\begin{array}{c}\text { Weekly } \\
\text { earnings }\end{array}$ & $\begin{array}{c}\text { Annual } \\
\text { earnings }\end{array}$ \\
\hline \multirow{2}{*}{ Years of education } & $0.086^{\star \star \star}$ & $0.090^{\star \star \star}$ & $0.103^{\star \star \star}$ \\
\cline { 2 - 4 } & $(0.005)$ & $(0.007)$ & $(0.007)$ \\
\hline \multirow{2}{*}{ Experience (years) } & $0.021^{\star \star \star}$ & $0.042^{\star \star \star}$ & $0.052^{\star \star \star}$ \\
\cline { 2 - 4 } & $(0.002)$ & $(0.003)$ & $(0.004)$ \\
\hline \multirow{2}{*}{ Experience squared/100 } & $-0.030^{\star \star \star}$ & $-0.073^{\star \star \star}$ & $-0.088^{\star \star \star}$ \\
\cline { 2 - 4 } & $(0.005)$ & $(0.007)$ & $(0.007)$ \\
\hline Constant & $1.937^{\star \star \star}$ & $5.447^{\star \star \star}$ & $9.067^{\star \star \star}$ \\
\cline { 2 - 4 } & $(0.071)$ & $(0.092)$ & $(0.103)$ \\
\hline R-squared & 0.127 & 0.111 & 0.105 \\
\hline Number of observations & 32775 & 32804 & 33613 \\
\hline
\end{tabular}

Sample: Unbalanced panel. Weighted numbers based on weights provided by HILDA. All regressions include year indicators. Robust standard errors, which are reported in parentheses, were adjusted to take repeated observations into account.

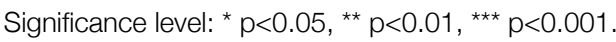

Source: Author's own calculations based on HILDA data.

Table 8.3 contains the estimates of the human capital earnings function for the sample of women. We find that an increase in education by one year (all else equal) increases hourly wages by 7.6 per cent. The corresponding relationship between education and weekly or annual earnings is 11.2 and 11.4 per cent, respectively. Empirical studies often find that the rate of return to education of female workers is higher than that of male workers. The smaller coefficient of education in the hourly wage regression stems from gender differences in full- and part-time employment.

Table 8.3: Returns to education of female workers: OLS estimates, 2001-14

\begin{tabular}{|l|c|c|c|}
\hline & Hourly wages & $\begin{array}{c}\text { Weekly } \\
\text { earnings }\end{array}$ & $\begin{array}{c}\text { Annual } \\
\text { earnings }\end{array}$ \\
\hline \multirow{2}{*}{ Years of education } & $0.076^{\star \star \star}$ & $0.112^{\star \star \star}$ & $0.114^{\star \star \star}$ \\
\cline { 2 - 4 } & $(0.003)$ & $(0.005)$ & $(0.005)$ \\
\hline \multirow{2}{*}{ Experience (years) } & $0.017^{\star \star \star}$ & $0.026^{\star \star \star}$ & $0.039^{\star \star \star}$ \\
\cline { 2 - 4 } & $(0.002)$ & $(0.004)$ & $(0.004)$ \\
\hline Experience squared/100 & $-0.027^{\star \star \star}$ & $-0.037^{\star \star \star}$ & $-0.055^{\star \star \star}$ \\
\cline { 2 - 5 } & $(0.005)$ & $(0.008)$ & $(0.010)$ \\
\hline
\end{tabular}




\begin{tabular}{|l|c|c|c|}
\hline \multirow{2}{*}{ Constant } & Hourly wages & $\begin{array}{c}\text { Weekly } \\
\text { earnings }\end{array}$ & $\begin{array}{c}\text { Annual } \\
\text { earnings }\end{array}$ \\
\hline R-squared & $2.057^{\star \star \star}$ & $4.836^{\star \star \star}$ & $8.543^{\star \star \star}$ \\
\cline { 2 - 4 } & $(0.041)$ & $(0.071)$ & $(0.081)$ \\
\hline Number of observations & 0.135 & 0.135 & 0.114 \\
\hline
\end{tabular}

Sample: Unbalanced panel. Weighted numbers based on weights provided by HILDA. All regressions include year indicators. Robust standard errors, which are reported in parentheses, were adjusted to take repeated observations into account.

Significance level: ${ }^{*} p<0.05,{ }^{* *} p<0.01,{ }^{* \star *} p<0.001$.

Source: Author's own calculations based on HILDA data.

The estimates in Table 8.4 translate the returns to education into earnings differentials between groups with different levels of education. The coefficients on educational attainment presented in Table 8.4 compare average earnings of male workers with certain levels of tertiary education to male workers with Year 12 and below.

Given the same level of labour market experience, we find that hourly wages of male workers with a postgraduate degree are 41.6 per cent higher than those of male workers with Year 12 and below. The hourly wage gap between male workers with a Bachelor or Honours degree and male workers with Year 12 and below is 37.4 per cent. An Advanced Diploma/ Diploma increases average hourly wages of male workers by 22.6 per cent if we compare them to those of male workers with Year 12 and below. Male workers with a Certificate I-IV earn on average 10.4 per cent more than male workers with Year 12 and below.

Table 8.4: Returns to education of male workers by level of education: OLS estimates, 2001-14

\begin{tabular}{|l|c|c|c|}
\hline \multirow{2}{*}{$\begin{array}{l}\text { Postgraduate Degree (Master's or } \\
\text { Doctorate) }\end{array}$} & Hourly wages & $\begin{array}{c}\text { Weekly } \\
\text { earnings }\end{array}$ & $\begin{array}{c}\text { Annual } \\
\text { earnings }\end{array}$ \\
\cline { 2 - 4 } & $0.416^{\star \star \star}$ & $0.436^{\star \star \star}$ & $0.499^{\star \star \star}$ \\
\hline \multirow{2}{*}{ Bachelor or Honours } & $(0.034)$ & $(0.043)$ & $(0.047)$ \\
\hline \multirow{2}{*}{ Advanced Diploma, Diploma } & $0.374^{\star \star \star}$ & $0.396^{\star \star \star}$ & $0.446^{\star \star \star}$ \\
\cline { 2 - 4 } & $(0.025)$ & $(0.030)$ & $(0.033)$ \\
\hline \multirow{2}{*}{ Certificate I-IV } & $0.226^{\star \star \star}$ & $0.249^{\star \star \star}$ & $0.265^{\star \star \star}$ \\
\cline { 2 - 4 } & $(0.025)$ & $(0.030)$ & $(0.036)$ \\
\hline & $0.104^{\star \star \star}$ & $0.153^{\star \star \star}$ & $0.178^{\star \star \star}$ \\
\cline { 2 - 4 } & $(0.018)$ & $(0.022)$ & $(0.025)$ \\
\hline
\end{tabular}




\begin{tabular}{|l|c|c|c|}
\hline \multirow{2}{*}{ Experience (years) } & Hourly wages & $\begin{array}{c}\text { Weekly } \\
\text { earnings }\end{array}$ & $\begin{array}{c}\text { Annual } \\
\text { earnings }\end{array}$ \\
\hline \multirow{2}{*}{ Experience squared/100 } & $0.021^{\star \star \star}$ & $0.040^{\star \star \star}$ & $0.051^{\star \star \star}$ \\
\cline { 2 - 4 } & $(0.002)$ & $(0.003)$ & $(0.004)$ \\
\hline \multirow{2}{*}{ Constant } & $-0.032^{\star \star \star}$ & $-0.073^{\star \star \star}$ & $-0.088^{\star \star \star}$ \\
\cline { 2 - 4 } & $(0.005)$ & $(0.007)$ & $(0.007)$ \\
\hline R-squared & $2.861^{\star \star \star}$ & $6.408^{\star \star \star}$ & $10.173^{\star \star \star}$ \\
\hline Number of observations & $(0.028)$ & $(0.039)$ & $(0.046)$ \\
\hline
\end{tabular}

Sample: Unbalanced panel. Weighted numbers based on weights provided by HILDA. All regressions include year indicators. Robust standard errors, which are reported in parentheses, were adjusted to take repeated observations into account. Reference category: Year 12 and below.

Significance level: ${ }^{*} p<0.05,{ }^{* \star} p<0.01,{ }^{* \star *} p<0.001$.

Source: Author's own calculations based on HILDA data.

We obtain similar earnings differentials when we use weekly or annual earnings instead of hourly wages as a dependent variable. The returns to labour market experience are slightly higher when we study weekly or annual earnings. Overall, the modified version of the human capital earnings function presented in Table 8.4 reveals that the returns to education are not necessarily constant across the educational distribution.

The picture changes somewhat when we consider earnings differentials between different levels of education within the group of female workers (Table 8.5). We find that hourly wages of female workers with a postgraduate degree are 38.4 per cent higher than those of female workers with Year 12 and below. The corresponding differences in weekly and annual earnings are 52.5 per cent and 51.2 per cent, respectively.

Table 8.5: Returns to education of female workers by level of education: OLS estimates, 2001-14

\begin{tabular}{|l|c|c|c|}
\hline \multirow{2}{*}{$\begin{array}{l}\text { Postgraduate Degree (Masters or } \\
\text { Doctorate)' }\end{array}$} & Hourly wages & $\begin{array}{c}\text { Weekly } \\
\text { earnings }\end{array}$ & $\begin{array}{c}\text { Annual } \\
\text { earnings }\end{array}$ \\
\cline { 2 - 4 } & $\left(0.384^{\star \star \star}\right.$ & $0.525^{\star \star \star}$ & $0.512^{\star \star \star}$ \\
\hline \multirow{2}{*}{ Bachelor or Honours } & $0.347^{\star \star \star}$ & $(0.031)$ & $(0.034)$ \\
\cline { 2 - 4 } & $(0.015)$ & $0.520^{\star \star \star}$ & $0.523^{\star \star \star}$ \\
\hline
\end{tabular}




\begin{tabular}{|l|c|c|c|}
\hline \multirow{2}{*}{ Advanced Diploma, Diploma } & Hourly wages & $\begin{array}{c}\text { Weekly } \\
\text { earnings }\end{array}$ & $\begin{array}{c}\text { Annual } \\
\text { earnings }\end{array}$ \\
\hline \multirow{2}{*}{ Certificate I-IV } & $0.155^{\star \star \star}$ & $0.271^{\star \star \star}$ & $0.281^{\star \star \star}$ \\
\cline { 2 - 4 } & $(0.018)$ & $(0.031)$ & $(0.034)$ \\
\cline { 2 - 4 } & -0.004 & 0.045 & 0.032 \\
\hline \multirow{2}{*}{ Experience (years) } & $(0.017)$ & $(0.026)$ & $(0.029)$ \\
\hline \multirow{2}{*}{ Experience squared/100 } & $0.017^{\star \star \star}$ & $0.027^{\star \star \star}$ & $0.040^{\star \star \star}$ \\
\cline { 2 - 4 } & $(0.002)$ & $(0.004)$ & $(0.004)$ \\
\hline \multirow{2}{*}{ Constant } & $-0.030^{\star \star \star}$ & $-0.041^{\star \star \star}$ & $-0.060^{\star \star \star}$ \\
\cline { 2 - 4 } & $(0.005)$ & $(0.008)$ & $(0.010)$ \\
\hline R-squared & $2.871^{\star \star \star}$ & $6.028^{\star \star \star}$ & $9.749^{\star \star \star}$ \\
\hline Number of observations & $(0.024)$ & $(0.039)$ & $(0.047)$ \\
\hline
\end{tabular}

Sample: Unbalanced panel. Weighted numbers based on weights provided by HILDA. All regressions include year indicators. Robust standard errors, which are reported in parentheses, were adjusted to take repeated observations into account. Reference category: Year 12 and below.

Significance level: ${ }^{*} p<0.05,{ }^{* \star} p<0.01,{ }^{* \star *} p<0.001$.

Source: Author's own calculations based on HILDA data.

We also observe that hourly wages of female workers with a Bachelor or Honours degree are 34.7 per cent higher than those of female workers with Year 12 and below. The weekly and annual earnings differentials between female workers with a Bachelor or Honours degree and female workers with Year 12 and below are about 52 per cent. Interestingly, the parameters associated with having a Bachelor or Honours degree are not significantly different from the earnings differentials observed for female workers with a postgraduate degree. This result suggests that female workers with a postgraduate degree work less and therefore do not translate their hourly wage premium into higher weekly or annual earnings than female workers with a Bachelor or Honours degree.

We find that hourly wages of female workers with an Advanced Diploma/ Diploma are 15.5 per cent higher than those of female workers with Year 12 and below. The weekly and annual earnings differentials between these two groups are about 27-28 per cent. Differences in earnings between female workers with a Certificate I-IV and female workers with Year 12 and below are not significantly different from zero, suggesting that the returns to vocational training of female workers are very low. The 
difference between the hourly wage regression and the earnings regressions presented in Table 8.5 may be attributed to the large share of part-time employed women.

\section{Life-cycle analysis}

Figure 8.4 presents the age-wage profiles of male workers based on the longitudinal model. We observe that the age-wage profiles of male workers are generally increasing at a relatively constant rate. Wages of male workers with a postgraduate degree grow much faster than those of male workers with a Bachelor or Honours degree after the age of 40 .

Wages of male workers with an Advanced Diploma/Diploma are typically about equal or higher than those of Certificate I-IV holders. Beyond age 55, male workers with an Advanced Diploma/Diploma earn even more than male workers with a Bachelor or Honours degree. The age-wage profile of male workers with Year 12 and below is consistently below the remaining profiles, indicating that the returns to education in relation to this reference group are always positive.

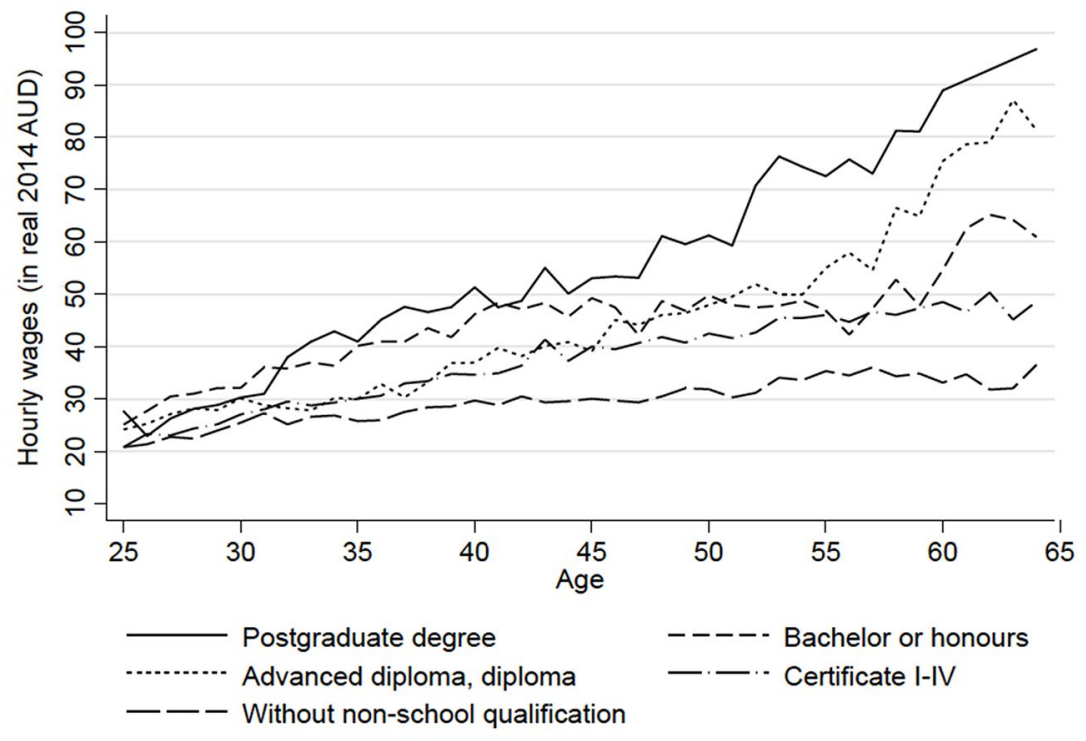

Figure 8.4: Age-wage profiles of male workers

Sample: Unbalanced panel. Weighted numbers based on weights provided by HILDA.

Source: Author's own calculations based on HILDA data. 
Figure 8.5 depicts the age-wage profiles of female workers, which are much lower than those of male workers. We observe linear increases in average wages over the life cycle. The profiles reveal that average earnings of female workers with a postgraduate degree do not differ substantially from those of female workers with a Bachelor or Honours degree. We also observe that differences between the remaining groups (Advanced Diploma/Diploma, Certificate I-IV and with Year 12 and below) are rather small, suggesting that the returns to vocational education of female workers are very low.

We use the age-wage profiles presented in Figures 8.4 and 8.5 to calculate the returns to education of male and female workers based on the present value of lifetime earnings. The age-wage profiles of workers with Year 12 and below are used as a reference group to obtain results that are comparable to the estimated earnings differentials reported in Tables 8.4 and 8.5.

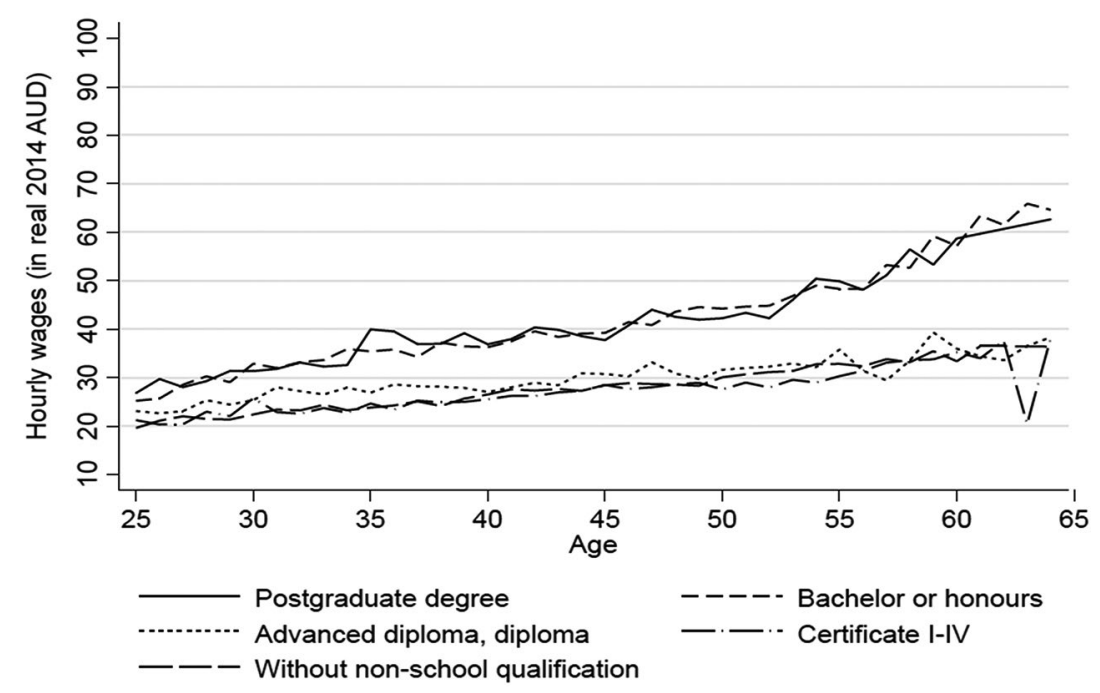

Figure 8.5: Age-wage profiles of female workers

Sample: Unbalanced panel. Weighted numbers based on weights provided by HILDA. Source: Author's own calculations based on HILDA data.

Panel A of Table 8.6 summarises the cross-sectional returns to education of male and female workers presented in Tables 8.4 and 8.5. We compare these results to the dynamic returns to education (Panel B) that were derived from calculating the present value of lifetime earnings using the age-wage profiles presented in Figures 8.4 and 8.5. Panel $\mathrm{C}$ takes into 
account that individuals with different levels of education exhibit different employment probabilities and adjusts the numbers of the dynamic returns to education accordingly.

The numbers in Table 8.6 indicate that the returns to education derived from the longitudinal analysis are quite different from those of the crosssectional analysis. We find that lifetime earnings of men with a postgraduate degree (Master's or Doctorate) are about 83 per cent higher than those of men with Year 12 and below (Panel C). Women with a postgraduate degree earn about 50 per cent more over their lifetime than women with Year 12 and below. The returns to education of both men and women with a Bachelor or Honours degree are about 50 per cent, indicating that women with a Bachelor or Honours degree earn about as much as women with a postgraduate degree. We also observe that women have no benefits from investing in vocational training. Overall, the empirical findings reveal considerable differences between cross-sectional and longitudinal models and between male and female workers.

Table 8.6: Returns to education of men and women (in per cent), cross-sectional vs life-cycle model

\begin{tabular}{|c|c|c|}
\hline & Men & Women \\
\hline \multicolumn{3}{|l|}{ A. Cross-sectional model } \\
\hline Postgraduate Degree (Master's or Doctorate) & 41.6 & 38.4 \\
\hline Bachelor or Honours & 37.4 & 34.7 \\
\hline Advanced Diploma, Diploma & 22.6 & 15.5 \\
\hline Certificate I-IV & 10.4 & -0.4 \\
\hline \multicolumn{3}{|l|}{ B. Life cycle model } \\
\hline Postgraduate Degree (Master's or Doctorate) & 77.1 & 47.1 \\
\hline Bachelor or Honours & 48.2 & 46.4 \\
\hline Advanced Diploma, Diploma & 41.8 & 8.2 \\
\hline Certificate I-IV & 22.6 & -2.1 \\
\hline \multicolumn{3}{|l|}{ C. Life cycle model, employment-adjusted } \\
\hline Postgraduate Degree (Master's or Doctorate) & 83.2 & 50.5 \\
\hline Bachelor or Honours & 51.9 & 49.1 \\
\hline Advanced Diploma, Diploma & 44.7 & 9.5 \\
\hline Certificate I-IV & 24.6 & -2.7 \\
\hline
\end{tabular}

Sample based on unbalanced panel. Weighted numbers based on weights provided by HILDA.

Source: Author's own calculations based on HILDA data. 


\section{Implications for gender differences in costs of higher education}

Although a detailed cost-benefit analysis is beyond the scope of this paper, we are able to study the implications of gender differences in earnings over the life course for the financial capacity of male and female university graduates to repay income-contingent student loans. Incomecontingent student loans in Australia are characterised by two important features. First, they provide default insurance because individuals who do not earn money do not have to repay. Second, they provide consumption smoothing because repayments depend on current income.

Modelling the implications of gender differences in earnings for the financial capacity of male and female university graduates to repay student loans requires the consideration of income and labour market dynamics. Cross-sectional earnings models assume that variation in earnings observed between individuals at a certain point in time persists in the future. Cross-sectional models ignore considerable variation in earnings, which may have important implications for the prediction of future earnings.

Higgins and Sinning (2013) use longitudinal data to address the shortcomings of cross-sectional earnings models. They find that observed characteristics explain a relatively small proportion of earnings variability. Unobserved differences can result from temporary variation (due to illness, higher duties, bonuses, overtime, etc.) or permanent variation (such as ability, talent or motivation). Additionally, permanent unobserved shocks may be the result of job mobility and promotions or demotions (Meghir and Pistaferri 2004) and other incidents not accommodated by observed transitions in labour force or life states. Temporary and permanent differences and shocks constitute unobserved variation in earnings between individuals and over time for the same individuals.

Variance component models may be used to capture temporary and permanent variation in earnings. Based on the seminal work of Lillard and Willis (1978) and MaCurdy (1982), econometricians have applied variance component models to the context of earnings dynamics over the last three decades. Higgins and Sinning (2013) use HILDA data and decompose the residuals of an earnings regression into a permanent and a transitory component. The estimates obtained from their dynamic earnings model may be used to simulate the unobserved components of 
the earnings equation and to predict future earnings of male and female university graduates in Australia. Higgins and Sinning (2013) use these earnings predictions to calculate the remaining average debt of 2001 university graduates over the period 2002-30.

Figures 8.6 and 8.7 depict the average outstanding debt of male university graduates resulting from actual and predicted earnings models. Debt levels predicted by Model E3 are close to actual debt levels because this model uses both a temporary and a permanent component to model unobserved variation. In contrast, Models E1 and E2 produce less realistic predictions because they assume that all unobserved variation is either temporary or permanent, respectively. The average debt at the start of the simulation period is assumed to be $\$ 25,000$ (in 2011 dollars). (See Higgins and Sinning (2013) for a detailed discussion of the underlying model assumptions.)

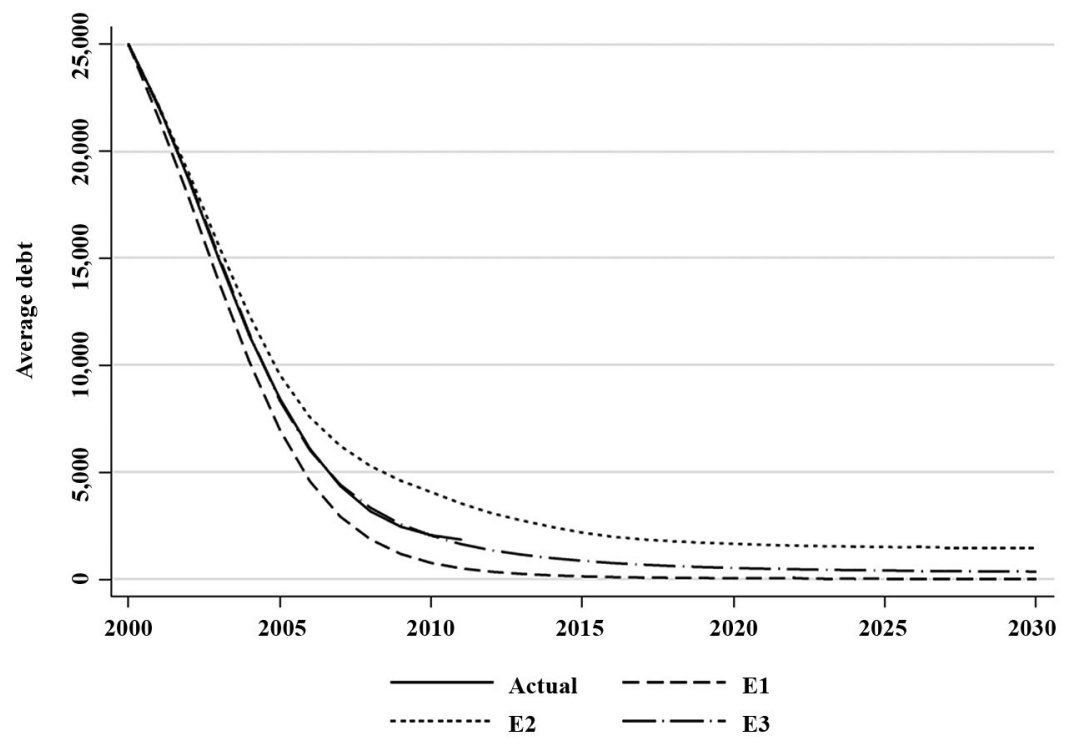

Figure 8.6: Average debt of male university graduates

Source: Higgins and Sinning (2013).

Figures 8.6 and 8.7 reveal considerable gender differences in actual and predicted outstanding debt levels. In particular, debt levels of male university graduates converge to zero over the projection period, while debt levels of female university graduates remain positive, indicating that many female university graduates do not have the financial capacity 
to repay their student loans in full. This result is remarkable because it implies that a considerable number of female university graduates rarely or never cross the minimum income threshold that would require them to repay their student loans. ${ }^{1}$ This implies that the proposal to reduce the HECS repayment threshold announced in the 2017-18 Budget will have a gendered impact.

Taken together, these findings indicate that gender differences in earnings have considerable implications for the capacity of male and female university graduates to repay their student loans. A substantial part of the implicit subsidy of HECS may be attributed to female university graduates who are unable to repay their student loans in full. Australian taxpayers take over this part of the overall cost of higher education.

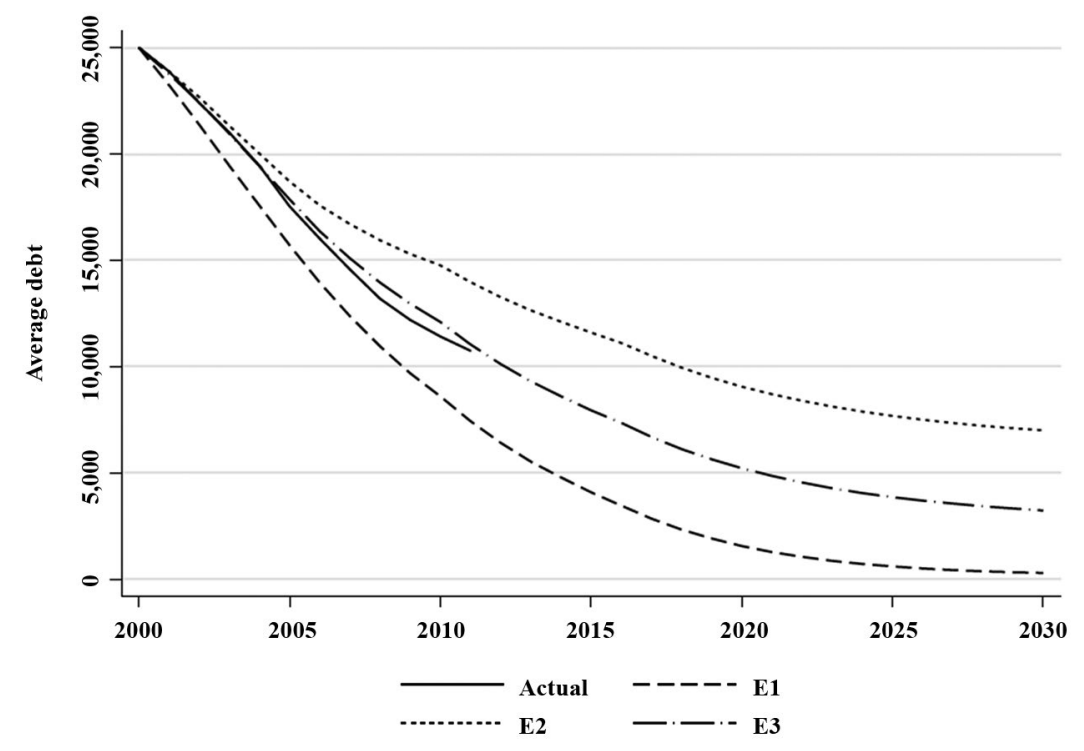

Figure 8.7: Average debt of female university graduates

Source: Higgins and Sinning (2013).

1 The model is based on the 2011 minimum income threshold of $\$ 44,912$ (in 2011 dollars). 


\section{Conclusions}

The results presented in this paper reveal a considerable earnings gap between men and women in Australia. Average earnings of male and female university graduates are about the same until about age 35 . While average earnings of men rise from about $\$ 40,000$ at age 35 to about $\$ 90,000$ at age 60 , average earnings of women increase only moderately from about $\$ 40,000$ at age 35 to about $\$ 55,000$ at age 60 . Gender earnings gaps at any given level of education may be attributed to a range of factors, including gender differences in labour force participation, full-time and part-time employment, occupational choices, labour market discrimination, etc. The differences are also consistent with the view that Australia is lagging behind most other OECD countries in matters of gender equality in the labour market: data from the OECD employment database 2014 confirm that the gender wage gap in Australia is above OECD average and that the gap has remained remarkably stable since the early 2000s (see data.oecd. org/earnwage/gender-wage-gap.htm).

This chapter uses longitudinal data from the HILDA Survey to present new calculations of the private returns to education in Australia. The data allow us to compare the estimates obtained from a cross-sectional model to those of a life-cycle model, which uses longitudinal data to predict earnings over the life cycle.

We find that lifetime earnings of men with a postgraduate degree (Master's or Doctorate) are about 83 per cent higher than those of men with Year 12 and below. Women with a postgraduate degree earn about 50 per cent more over their lifetime than women with Year 12 and below. Our findings also reveal that women with a Bachelor or Honours degree earn almost as much as women with a postgraduate degree. We further observe that women have no benefits from investing in vocational training. Overall, the empirical findings reveal considerable differences between cross-sectional and longitudinal models and between male and female workers. Further research is needed to gain a better understanding of the factors that are responsible for the findings presented in this paper.

Our results for HECS debt calculations presented in the last section are a result of the considerable gender earnings gap. One could argue that HECS contributes to gender differences in earnings by subsidising female university graduates and thereby creating disincentives for women to work, but it appears likely that the effect of HECS on female labour force 
participation is rather small or insignificant. At the same time, HECS plays a critical role in the context of gender differences in earnings because the scheme provides default insurance and consumption smoothing to female university graduates and ensures that both men and women from low socio-economic backgrounds are able to obtain a university degree. The contributions of HECS to social mobility are likely to outweigh any potential negative side effects on work disincentives of female university graduates. HECS is particularly interesting from a public policy perspective because the scheme reduces economic inequality while potentially contributing to economic growth. Tax and transfer policies that aim to reduce economic inequality (such as social welfare payments) typically contribute to lower economic growth.

\section{References}

Angrist, Joshua and Alan Krueger. 1991. 'Does Compulsory Schooling Attendance Affect Schooling and Earnings?' Quarterly Journal of Economics 106(4): 979-1014. doi.org/10.2307/2937954

Ashenfelter, Orley, Colm Harmon and Hessel Oosterbeek. 1999. 'A Review of Estimates of the Schooling/Earnings Relationship, with Tests for Publication Bias'. Labour Economics 6(4): 453-470. doi. org/10.1016/S0927-5371(99)00041-X

Ashenfelter, Orley and Alan Krueger. 1994. 'Estimates of the Economic Return to Schooling from a New Sample of Twins'. The American Economic Review 84: 1157-1173.

Becker, Gary. 1964. Human Capital: A Theoretical and Empirical Analysis with Special Reference to Education. New York: Columbia University Press.

Card, David. 1999. 'The Causal Effect of Education on Earnings'. In Orley Ashenfelter and David Card (eds), Handbook of Labor Economics. Amsterdam: Elsevier. doi.org/10.1016/s1573-4463(99)03011-4

Daly, Anne and Philip Lewis. 2010. 'The Private Rate of Return to an Economics Degree in Australia: An Update'. Economic Papers 29(3): 353-364. doi.org/10.1111/j.1759-3441.2010.00072.x 
Daly, Anne, Philip Lewis, Michael Corliss and Tiffany Heaslip. 2010. The Private Rate of Return to a University Degree in Australia. University of Canberra, Centre for Labour Market Research, Canberra.

Heckman, James, Lance Lochner and Petra Todd. 2005. 'Earnings Functions, Rates of Return, and Treatment Effects: The Mincer Equation and Beyond'. In Eric A. Hanushek and Finis Welch (eds), Handbook of the Economics of Education, Volume 1. Amsterdam: Elsevier. doi.org/10.3386/w11544

Higgins, Timothy and Mathias Sinning. 2013. 'Modeling Income Dynamics for Public Policy Design: An Application to Income Contingent Student Loans'. Economics of Education Review 37: 273-285. doi.org/10.1016/j.econedurev.2013.08.009

Jaeger, David and Marianne Page. 1996. 'Degrees Matter: New Evidence on Sheepskin Effects in the Returns to Education'. Review of Economics and Statistics 78(4): 733-740. doi.org/10.2307/2109960

Leigh, Andrew and Christopher Ryan. 2008. 'Estimating Returns to Education using Different Natural Experiment Techniques'. Economics of Education Review 27(2): 149-160. doi.org/10.1016/j. econedurev.2006.09.004

Lillard, Lee and Robert Willis. 1978. 'Dynamic Aspects of Earning Mobility'. Econometrica 46(5): 985-1012. doi.org/10.2307/1911432

MaCurdy, Thomas. 1982. 'The Use of Time Series Processes to Model the Error Structure of Earnings in a Longitudinal Data Analysis'. Journal of Econometrics 18(1): 83-114. doi.org/10.1016/0304-4076(82)90096-3

Marks, Gary. 2008. 'The Occupations and Earnings of Young Australians: The Role of Education and Training'. Longitudinal Study of Australian Youth (LSAY) Research Report No. 55. doi.org/10.1111/j.14680262.2004.00476.x

Meghir, Costas and Luigi Pistaferri. 2004. 'Income Variance Dynamics and Heterogeneity'. Econometrica 72(1): 1-32.

Mincer, Jacob. 1974. Schooling, Experience and Earnings. New York: National Bureau of Economic Research.

Norton, Andrew. 2012. Graduate Winners-Assessing the Public and Private Benefits of Higher Education. Melbourne: Grattan Institute. 
OECD (Organisation for Economic Co-operation and Cultural Development). 2015. Education at a Glance: OECD Indicators. Paris: OECD Publishing.

Psacharopoulos, George and Harry Anthony Patrinos. 2004. 'Returns to Investment in Education: A Further Update'. Education Economics 12(2): 111-135. doi.org/10.1080/0964529042000239140

Schultz, Theodore. 1961. 'Investment in Human Capital'. The American Economic Review 51(1): 1-17.

Wei, Hui. 2010. Measuring Economic Returns to Post-School Education in Australia. Research Paper Cat. no. 1351.0.55.032, Canberra: Australian Bureau of Statistics. 
This text is taken from Tax, Social Policy and Gender: Rethinking equality and efficiency, edited by Miranda Stewart, published 2017 by ANU Press, The Australian National University, Canberra, Australia.

dx.doi.org/10.22459/TSPG.11.2017.08 